\title{
Perencanaan Lingkungan dan Rumah Tanggap Bencana di Pulau Sapuli Kabupaten Pangkajene dan Kepulauan, Sulawesi Selatan
}

\author{
Ria Wikantari*, Rahmi Amin Ishak, Imriyanti, Abd. Mufti Radja \\ Departemen Arsitektur, Fakultas Teknik UNHAS, \\ wikantaria@gmail.com*
}

\begin{abstract}
Abstrak
Pulau Sapuli merupakan salah satu pulau kecil di lepas pantai Kabupaten Pangkajene Kepulauan, memiliki luas 2,24 Ha yang dihuni oleh 125 kepala keluarga dan berkepadatan populasi 213 jiwa/Ha. Pulau ini telah mengalami abrasi yang signifikan terutama pada sisi bagian Barat dan Utara pulau. Umumnya bangunan rumah di Pulau Sapuli berupa rumah panggung, sebagai ciri arsitektur tradisional yang memiliki bentuk adaptif terhadap bencana alam. Permasalahan yang terjadi di wilayah pulau Sapuli adalah pertumbuhan permukiman yang tidak terkendali dan rumah penduduk yang umumnya tidak siaga bencana dari segi pengembangan hunian (ruang rumah), struktur dan konstruksi rumah serta material rumah. Tujuan artikel kajian pengabdian ini adalah pemberian informasi berupa sosialisasi lingkungan dan rumah yang tanggap bencana, mencakup; aspek tata lingkungan dan bangunan rumah tinggal. Kajian ini merupakan tahapan yang dilaksanakan berdasarkan hasil-hasil dari identifikasi fisik dan non fisik wilayah, terkait kearifan lokal setempat dan pendekatan pada masyarakat yang disesuaikan dengan analisis yang dilakukan, sehingga dapat dihasilkan prioritas terhadap kebutuhan akan lingkungan dan rumah yang tanggap bencana. Implementasi kajian pengabdian ini dilaksanakan oleh Departemen Arsitektur Unhas dengan jumlah peserta sebanyak 10 orang, kegiatan ini diharapkan dapat menumbuhkan kesadaran masyarakat akan pentingnya lingkungan dan rumah tanggap bencana sebagai upaya peningkatan kualitas hidup masyarakat dan lingkungan pulau kecil.
\end{abstract}

Kata Kunci: Lingkungan; Rumah Tinggal; Tanggap Bencana; Pulau Kecil.

\section{Pendahuluan}

Kabupaten Pangkajene Kepulauan (Pangkep) di Sulawesi Selatan merupakan salah satu daerah yang sebagian besar luasan wilayahnya merupakan perairan berisi pulau-pulau kecil bagian dari Kepulauan Spermonde. Sebagian pulau merupakan wilayah berpenghuni dengan kepadatan penduduk sangat tinggi, sebagian lain merupakan wilayah tak berpenghuni dengan keberagaman terumbu karang yang sangat tinggi, terutama di Kepulauan Kapoposang dan sekitar. Wilayah Spermonde di Pangkep tak terlepas dari persoalan kerentanan terhadap bencana alam marin. Frekuensi dan intensitas kejadian bencana cenderung meningkat. Risiko bencana pun semakin besar pada pulau-pulau berpenghuni dengan kepadatan penduduk tinggi seperti Pulau Sapuli.

Luas daratan Sapuli saat ini sebesar $2.24 \mathrm{Ha}$, merupakan penyusutan $\pm 10 \%$ dibanding luas 2.5 Ha pada tahun 2010. Sekitar 25\% dari 620 m pantai pun mengalami abrasi (Gambar 1). Keadaan tersebut sejalan dengan pengamatan awal yang menunjukkan telah terjadinya abrasi akibat kejadian gelombang ekstrim. Jejak abrasi ditemukan di sekeliling pulau dengan kondisi terparah pada sisi Barat, Barat Laut, dan Utara. 


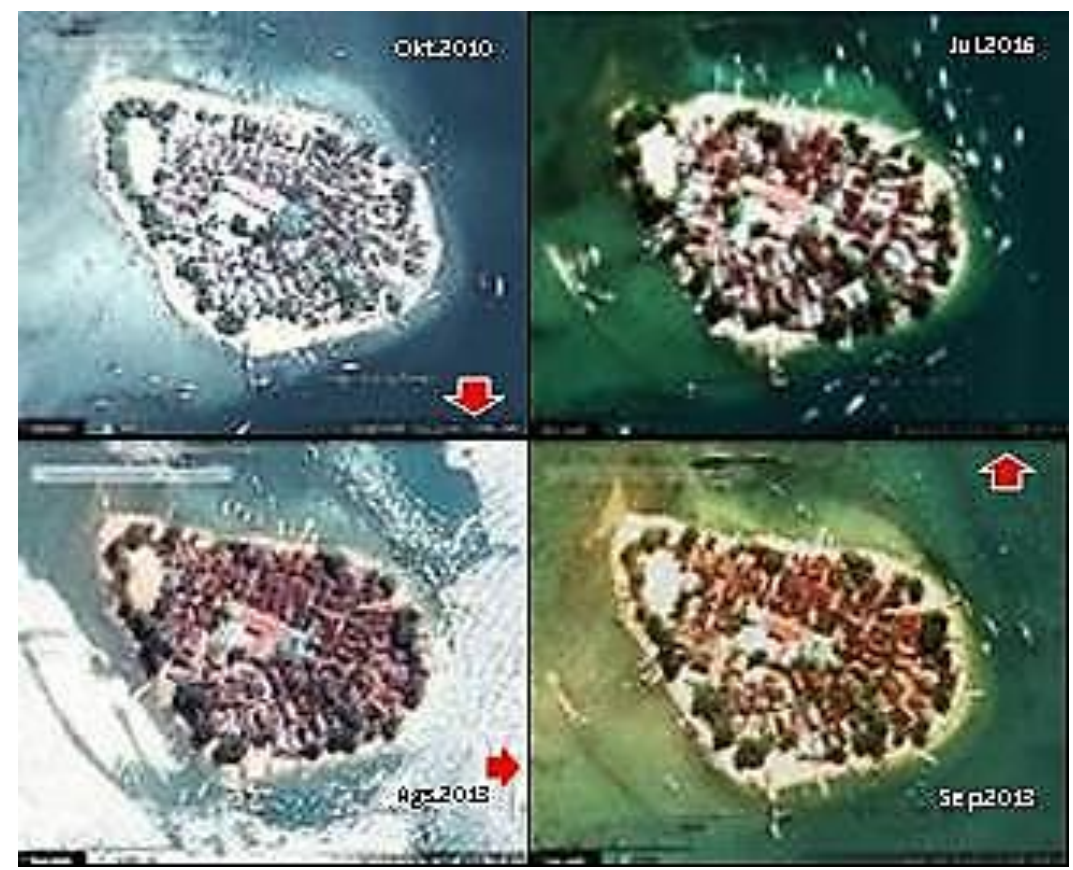

Gambar 1. Timelines Pulau Sapuli 2010-2013-2016

(Google Earth, 2016)

Kajian pengabdian masyarakat ini bertujuan mengimplementasikan perencanaan lingkungan dan rumah yang tanggap bencana, terutama ditinjau dari aspek keselamatan dan keamanan yang mencakup; tata bangunan, bentuk bangunan, penataan ruang rumah, sistem konstruksi dan bahan bangunan. Hasil pengabdian masyarakat ini, diharapkan dapat menambah wawasan meningkatkan kapasitas, kemampuan dan kemandirian masyarakat di pulau kecil, mengaplikasikan ilmu pengetahuan dan teknologi tentang lingkungan dan rumah tanggap bencana di Pulau Sapuli.

\section{Latarbelakang Teori}

Dahuri dkk (1996) menyatakan bahwa kawasan pulau memiliki beberapa elemen bencana alam yaitu angin kencang/puting beliung, gempa bumi, tsunami, gelombang badai pasang, banjir dan gerakan tanah. Selanjutnya ada empat elemen sebagai akibat dari bencana alam yaitu abrasi, akresi, erosi dan instusi air laut. Menurut Nasiah dan Suprapta (2010) cara pengelolaan pantai yang telah dilakukan pemerintah dan masyarakat untuk mengantisipasi bencana alam marin yaitu: pembuatan talud/tembok pelindung pantai, breaker silinder untuk pemecah ombak, bronjong, groin, dan tanaman bakau/mangrove. Berdasarkan karakteristik lahan di pantai Barat wilayah Sulawesi Selatan maka diarahkan 4 tipe pengelolaan yaitu: pembudidayaan tanaman tapak kaki kambing sebagai penahan erosi pantai, penanaman mangrove, pembiakan terumbu karang, dan yang bersifat struktur fisik adalah pembuatan talud. Diposaptono (2014) secara teknis menyatakan tentang bangunan fisik buatan dan keamanan terhadap bencana, bahwa: bangunan dengan banyak pintu dan jendela relatif aman terhadap bencana gelombang laut ekstrim termasuk tsunami; bangunan berpanggung aman terhadap bencana gelombang laut ekstrim; bangunan dengan posisi orientasi tegak lurus terhadap garis pantai relatif aman terhadap bencana tersebut, demikian pula deretan pohon yang membentuk sabuk hijau/greenbelt dapat meredam bencana. 
Bengen \& Tahir (2012) mengungkap bahwa adaptasi struktural atau fisik mencakup adaptasi struktural alami termasuk peningkatan dan perbaikan ekosistem pesisir dan pulau kecil seperti: mangrove, rumput laut, terumbu karang. Adaptasi struktural buatan/artifisial termasuk pemecah ombak, dinding pelindung/talud, tanggul/levees, naungan/shelter, struktur ber-panggung, dan pembiakan terumbu karang. Bangunan rumah tanggap bencana dan ramah lingkungan pesisir dan pulau-pulau kecil adalah tipe berpanggung, dan, tipe satu lantai tak berpanggung dengan struktur pondasi solid.

Permen Perumahan No. 8 tahun 2007, menyebutkan bahwa rumah layak huni adalah bangunan rumah yang sekurang-kurangnya memenuhi persyaratan keselamatan bangunan dan kecukupan minimum luas ruang serta kesehatan penghuninya. Keselamatan bangunan ditinjau dari sisi kekokohan pondasi yang mampu mendukung dan melindungi dari pengaruh alam. Kecukupan minimum luas ruang berkaitan dengan pemenuhan standar minimum luas ruang gerak manusia dalam rumah. Kesehatan penghuni dimaksudkan agar penghuninya terjamin kesehatannya dari pengaruh lingkungan. Rumah sehat dan layak huni di wilayah pulau kecil selayaknya juga mempertimbangkan aspek kenyamanan dan kesehatan keselamatan, serta keamanan. Aspek kenyamanan dan kesehatan meliputi penghawaan atau aliran udara, pencahayaan dan kelembaban dalam ruang rumah. Aspek keselamatan mencakup ketahanan konstruksi bangunan terhadap bencana seperti gempa, angin, gelombang pasang, abrasi. Sedangkan dari aspek keamanan, rumah dapat memberikan rasa aman.

Kajian implementasi pengabdian kepada masyarakat ini diharapkan dapat membantu menangani masalah akan kebutuhan masyarakat terhadap lingkungan dan rumah tinggal (struktur dan konstruksi bangunan serta material hunian) yang tanggap terhadap bencana di pulau Sapuli Kabupaten Pangkajene Kepulauan. Kajian ini juga sekaligus memberikan arahan pendekatan dalam bentuk partisipasi masyarakat berdasarkan informasi dan saran dari masyarakat setempat untuk dijadikan acuan dalam pelaksanaan perencanaan lingkungan dan pembangunan rumah tanggap bencana di wilayah pulau kecil. Soetrisno, L (1995) menyebutkan partisipasi adalah kerja sama antara rakyat dan pemerintah dalam merencanakan, melaksanakan, melestarikan, dan mengembangkan hasil pembangunan. Masyarakat harus ikut secara aktif dalam menentukan dan menjalankan upaya dan program bantuan dari pemerintah, dan dengan demikian dapat menentukan keadaan hidup masyarakat mulai dari saat pengambilan keputusan, pelaksanaan, pengawasannya hingga perawatan suatu program. Berjalannya proses-proses dalam pengembangan masyarakat secara partisipatif adalah suatu kontribusi signifikan warga negaranya merupakan proses yang diharapkan dan normal dalam suatu upaya pembuat keputusan.

\section{Metode}

Lokasi kegiatan dilaksanakan di Pulau Sapuli Kabupaten Pangkajene dan Kepulauan, Propinsi Sulawesi Selatan. Sasaran program diperuntukkan bagi masyarakat di kepulauan dalam merencanakan lingkungan dan rumah tanggap bencana. Kegiatan telah dilaksanakan pada bulan Juni hingga Oktober 2016, dimulai dari tahap persiapan survey awal hingga tahap pelaksanaan sosialisasi perencanaan di Pulau Sapuli.

Pada tahap persiapan dilakukan survey lokasi untuk mendapatkan gambaran kondisi fisik dan non fisik wilayah pulau, mencakup; topografi, pola permukiman, rumah penduduk, dan data penduduk. Kegiatan FGD dengan masyarakat, aparat pemerintah, dan tokoh masyarakat, sebagai partisipasi langsung dari masyarakat dalam memberikan informasi permasalahan yang terjadi di 
pulau Sapuli dan kebutuhan masyarakat terkait perencanaan lingkungan dan rumah yang tanggap bencana.

Tahap pelaksanaan dilakukan kajian perencanaan lingkungan dan rumah yang tanggap bencana, berdasarkan hasil FGD dan informasi dari masyarakat tentang kondisi rumah dan bencana yang sering terjadi di pulau tersebut. Hal ini untuk mendapatkan data-data primer perencanaan, dan selanjutnya pelaksanaan kegiatan sosialisasi hasil kajian dengan melibatkan unsur masyarakat, aparat pemerintah dan tokoh masyarakat.

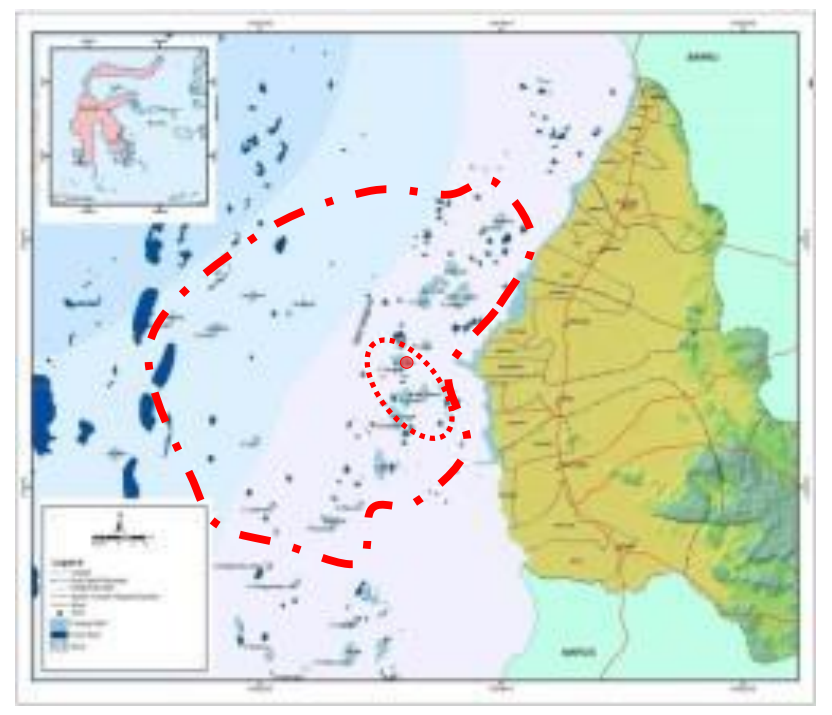

Gambar 2. Peta letak Pulau Sapuli, Kabupaten Pangkep

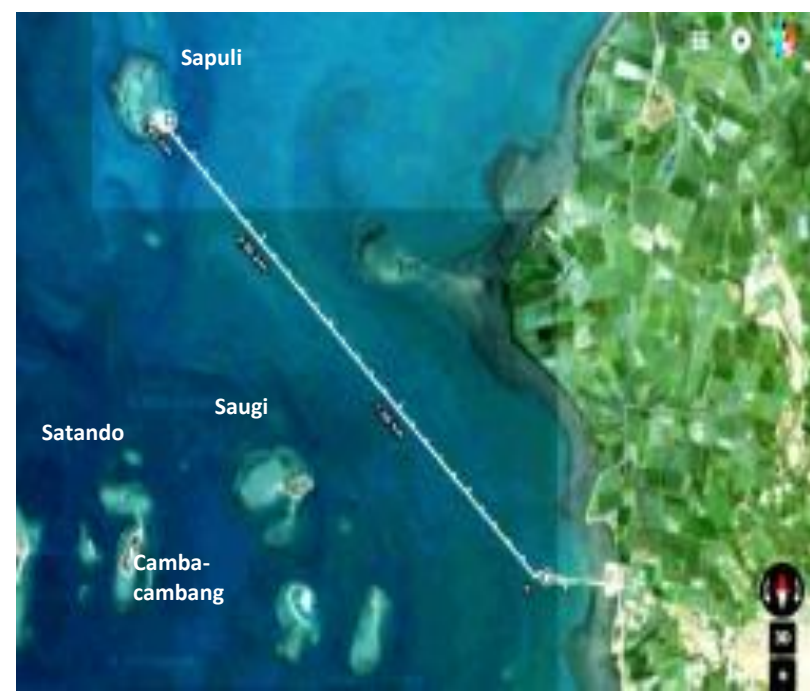

Gambar 3. Letak Pulau Sapuli dari Pelabuhan Maccini Baji, Kabupaten Pangkep 


\section{Hasil dan Diskusi}

Data awal dalam merumuskan perencanaan lingkungan dan rumah yang tanggap bencana adalah hasil FGD aspirasi masyarakat, hasil observasi dan identifikasi lokasi. Hasil FGD menekankan pada permasalahan:

- Kondisi dan kualitas lingkungan, bangunan, dan vegetasi

- Tipe, bentuk, selubung, dan massa bangunan yang layak dan tanggap bencana

- Struktur, konstruksi, dan material bangunan yang layak dan tanggap bencana

Hasil identifikasi lokasi, dipaparkan dalam bagian berikut ini.

\section{Kondisi Lingkungan, Bangunan, dan Vegetasi}

Fasilitas lingkungan terbagi atas: Infrastruktur teknis berupa jalan lingkungan, sumur bor air bersih, saluran pembuangan, generator listrik, tanggul pantai, pelindung ombak lepas pantai, dan 2 dermaga. infrastruktur sosial berupa MCK umum, mesjid, sekolah, posyandu, puskesmas. Letak sarana sosial utama seperti mesjid dan sekolah berada di tengah pulau, sedangkan MCK terdapat di beberapa kelompok unit hunian. Selain itu terdapat vegetasi tipe pohon sejumlah 53 batang, sedangkan 6 batang telah tumbang oleh badai 10 tahun terakhir.

Keterbatasan lahan pulau mendorong penduduk terkhusus keluarga/KK baru memanfaatkan kolong rumah untuk menambah kebutuhan luas ruang di rumah berpanggung, atau membangun ke samping bergandeng dengan rumah inti. Pada rumah tak-berpanggung penambahan hanya dapat dikembangkan ke sisi pada sisa persil yang ada. Akibatnya, terjadi pemadatan bangunan secara vertikal 2 lantai maupun secara horizontal. Sejumlah $125 \mathrm{KK}$ yang terdiri atas 477 jiwa bertempat tinggal dalam 92 unit hunian. Jalan lingkungan dengan lebar variatif antara 1.5-2.0 m berpola tidak tertata baik cenderung tidak teratur. Kepadatan bangunan sangat tinggi dengan jarak antarbangunan $0.5-0.8 \mathrm{~m}$. Meskipun demikian masih terdapat ruang terbuka pada ujung Barat pulau, berjarak \pm 30 meter dari tepi pulau ke rumah penduduk, dengan pemakaman lama terdapat di sisi Utara.

Vegetasi terdapat di sekeliling tepian pulau, terutama dari jenis tanaman peneduh seperti: ketapang, sukun, asam; tanaman tajuk sedang seperti kelor dan cemara pantai; dan jenis tanaman perdu. Bakau sebagai barrier terdapat di sisi Barat. Vegetasi tersebut memberikan iklim mikro yang baik pada pulau, sekaligus sebagai pengikat air tanah di musim kemarau, dan pelindung dari hembusan angin ekstrim di musim muson barat.

a.

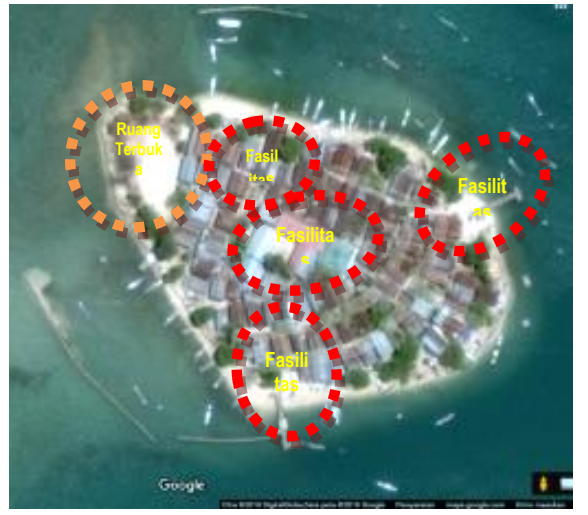

$\mathrm{b}$

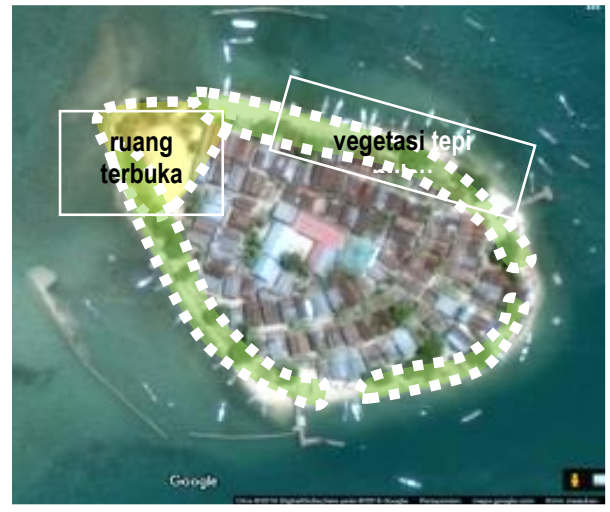




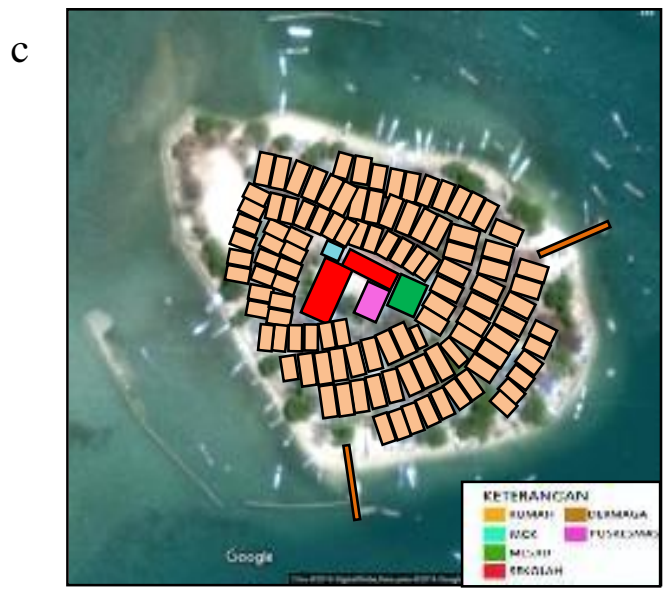

Gambar 4. Kondisi lokasi: a) Fasilitas Lingkungan; b) Letak Bangunan; c) Letak Vegetasi

\section{Tipe, Struktur, dan Massa Bangunan}

(1) Tipe bangunan: terdapat 3 tipe ditinjau dari konfigurasi panggung, yaitu (i) tipe bangunan berpanggung, dengan beberapa kemungkinan konfigurasi panggung: berkolong terbuka total, berkolong terbuka sebagian besar, berkolong tertutup sebagian besar, ataupun berkolong tertutup total, (ii) tipe bangunan tak-ber-panggung 1 lantai; (iii) tipe bangunan tak-ber-panggung bertingkat 2 lantai. Penutupan kolong sebagian ataupun total pada bangunan yang aslinya bangunan berpanggung merupakan upaya pemenuhan ruang hunian seturut per-kembangan jumlah anggota keluarga ataupun penambahan unit rumahtangga. Demikian pula terjadi pada penggantian tipe bangunan ber-panggung ataupun tak-berpanggung 1 lantai menjadi tipe bangunan tak-berpanggung ber-tingkat 2 lantai. Tipe bangunan berpanggung memungkinkan penerusan pengaliran air melewati kolong bangunan pada saat terjadi banjir akibat hempasan gelombang ekstrim ataupun pada saat pasang naik ekstrim akibat pengaruh peningkatan tingkat permukaan laut (Sea Level Rise/SLR). Tipe bangunan tak-berpanggung 1 lantai dengan penguatan pondasi permanen dan struktur bangunan betingkat 2 lantai memungkinkan pengalihan ataupun pembelokan aliran air, mencegah masuknya ke dalam bangunan.

(2) Struktur bangunan: dibedakan menjadi struktur bangunan rangka kayu dengan dinding papan, dan, struktur bangunan rangka beton dengan dinding bata/batako. Struktur pertama bersifat semipermanen, sedangkan yang kedua permanen. Di Sapuli terdapat bangunan struktur rangka kayu dengan dinding kayu tak-permanen yang dikelilingi dengan pondasi pasangan batu permanen. Juga terdapat bangunan panggung struktur rangka kayu dengan dinding kayu tak-permanen yang bagian kolong lantai dasarnya 'dibungkus' dengan dinding permanen berangka beton menjadi struktur 'hibrid'. Sistem struktur spesifik dengan penambahan struktur permanen pada struktur semi-permanen demikian dimaksudkan untuk penguatan menghadapi paparan badai dan gelombang ekstrim.

(3) Massa bangunan: berbentuk dasar persegi empat atau persegi panjang, cenderung membentuk massa bangunan kompak. Dimensi bangunan memiliki lebar berkisar 6.0-10.0 m, panjang 7.5-12 m, dan tinggi badan bangunan 3.5-7.0 m, membentuk proporsi netral sehingga mendukung kestabilan massa bangunan ter-hadap paparan gaya lateral terpaan badai. 
(4) Bentuk atap: memiliki bentuk khas tradisional sesuai arsitektur lokal suku Bugis-Makassar, yaitu bentuk atap pelana. Bentuk ini memungkinkan penembusan aliran angin arah longitudinal bangunan dari kedua ujung atap, maupun membelokkan aliran angin arah transversal bangunan pada permukaan kedua sisi atap apabila terbuat dari bahan tak bercelah seperti lembaran plat seng.

(5) Fasade bangunan: dinding sekeliling pada bangunan rangka kayu umumnya berupa dinding pembatas non-struktural terbuat dari bahan papan kayu ataupun bambu yang bercelah-celah. Pembatas ini bersifat 'tirai-mirai', memungkinkan penerusan terpaan angin ekstrim selain melalui bukaan pintu dan jendela juga melalui celah-celah material dinding. Pada bangunan berstruktur dinding permanen keberadaan struktur atap berbentuk pelana pun memungkinkan bukaan ventilasi ataupun celah-celah material pada kedua ujung atap, sehingga memungkinkan pengaliran hembusan angin ekstrim sebagaimana pada dinding.
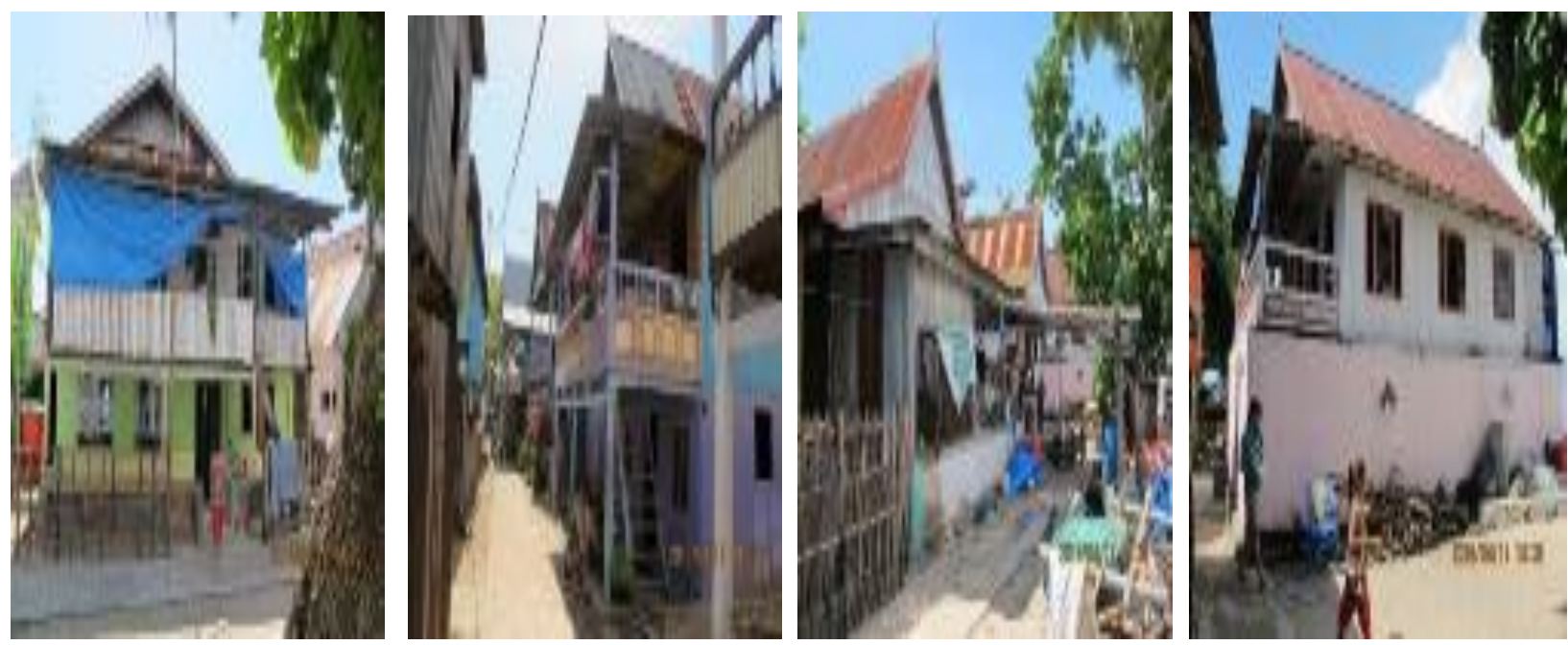

Gambar 5. Keragaman Bangunan di Pulau Sapuli

Tabel 1. Hasil Kajian Lingkungan dan Rumah Tanggap Bencana di Pulau Sapuli

\begin{tabular}{|c|c|c|}
\hline Unsur Amatan & Kondisi Eksisting & Tanggap Bencana \\
\hline \multicolumn{3}{|l|}{ Lingkungan } \\
\hline Lokasi bangunan & $\begin{array}{l}\text { Memenuhi seluruh bagian, di tepian } \\
\text { maupun di tengah pulau; Tidak berlaku } \\
\text { ketentuan umum batas sempadan pantai; } \\
\text { Tanggul tepi pantai rusak oleh abrasi }\end{array}$ & \\
\hline $\begin{array}{l}\text { Orientasi } \\
\text { bangunan }\end{array}$ & $\begin{array}{l}\text { Serong dan diagonal arah Barat Laut- } \\
\text { Tenggara, dan Barat Daya-Timur Laut }\end{array}$ & $\begin{array}{l}\text { Searah aliran angin Muson } \\
\text { Barat dan Timur }\end{array}$ \\
\hline $\begin{array}{l}\text { Jarak antar } \\
\text { bangunan }\end{array}$ & $\begin{array}{l}\text { Bangunan rapat berhimpit, menyisakan } \\
\text { jarak minim berupa celah antarbangunan; } \\
\text { Kelompok bangunan membentuk } \\
\text { kesatuan massa dengan celah bangunan }\end{array}$ & $\begin{array}{l}\text { Lorong angin untuk akses } \\
\text { aliran badai }\end{array}$ \\
\hline \multicolumn{3}{|l|}{ Arsitektur } \\
\hline Tipe Bangunan & $\begin{array}{l}\text { Berpanggung; Tak-berpanggung } 1 \text { lantai } \\
\text { dengan penguatan pondasi; Tak- }\end{array}$ & $\begin{array}{l}\text { Penerusan ataupun penahanan } \\
\text { aliran air akibat gelombang }\end{array}$ \\
\hline
\end{tabular}




\begin{tabular}{|l|l|l|}
\hline \multicolumn{1}{|c|}{ Unsur Amatan } & \multicolumn{1}{|c|}{ Kondisi Eksisting } & \multicolumn{1}{c|}{ Tanggap Bencana } \\
\hline $\begin{array}{l}\text { Struktur } \\
\text { Bangunan }\end{array}$ & $\begin{array}{l}\text { Rangka kayu dengan dinding semi- } \\
\text { permanen; Rangka beton dengan } \\
\text { dinding permanen; Rangka kayu dengan } \\
\text { kolong dibungkus dinding permanen } \\
\text { (hibrid) }\end{array}$ & $\begin{array}{l}\text { Struktur lentur, Struktur kaku, } \\
\text { Struktur hibrid }\end{array}$ \\
\hline Massa bangunan & Kompak, proporsi netral & Stabilitas terhadap gaya lateral \\
\hline Bentuk atap & $\begin{array}{l}\text { Pelana dengan ventilasi/bukaan pada } \\
\text { kedua ujung; Bidang atap miring pada } \\
\text { kedua sisi }\end{array}$ & $\begin{array}{l}\text { Lorong angin untuk akses } \\
\text { aliran badai }\end{array}$ \\
\hline $\begin{array}{l}\text { Fasade dan } \\
\text { selubung } \\
\text { bangunan }\end{array}$ & Tirai-mirai & $\begin{array}{l}\text { Celah-celah angin mencegah } \\
\text { hempasan badai }\end{array}$ \\
\hline
\end{tabular}

\section{Implementasi Kajian}

Berdasarkan hasil kajian lingkungan dan pedoman SNI 03-1733-2011, maka implementasi perencanaan lingkungan, mencakup:

(1) Pola permukiman sedapat mungkin teratur, bangunan sejajar dengan arah penjalaran gelombang pasang dan tsunami atau tegak lurus dengan garis pantai agar air gelombang pasang mempunyai ruang dan tekanan air yang relatif kecil.

(2) Pola permukiman dengan pola grid, memungkinkan adanya koridor (tegak lurus terhadap garis pantai) jalan lingkungan sebagai akses dan ruang aliran air gelombang pasang.

(3) Sisi lebar bangunan dibuat sejajar dengan garis pantai sehingga mengurangi tekanan air (gelombang pasang, tsunami) dan angin (angin musim) menerpa bangunan. Sisi terpendek bangunan tegak lurus terhadap tepi pantai dengan orientasi laut $\&$ jalur sirkulasi.

(4) Lokasi permukiman harus jauh terhadap zona paling rawan terkena gelombang ekstrim, minimal setback $200 \mathrm{~m}$ atau dengan radius $>500 \mathrm{~m}$ dari bibir pantai.

(5) Arah angin sangat menentukan orientasi bangunan. Rumah yang terletak di baris pertama dari laut sebaiknya mengurangi bukaan, sebab angin yang datang sangat kencang. Terutama bila tidak ada vegetasi yang mereduksi tekanan angin.

(6) Orientasi bangunan berkaitan dengan bentuk bangunan, sebab bentuk bangunan mempengaruhi besarnya tekanan angin. Makin tinggi bangunan semakin besar tekanan anginnya. Sisi lebar sebaiknya tegak lurus terhadap arah angin, untuk mengurangi bidang terluas dari bangunan.

(7) Bangunan dibuat sejajar dengan penjalaran gelombang pasang atau tegak lurus terhadap garis pantai, agar tekanan air dan angin yang menghantam bangunan lebih kecil.

Hasil kajian bangunan di Pulau Sapuli, perencanaan rumah tinggal mencakup:

(1) Tipe bangunan berpanggung dengan penguatan pondasi yang dapat meneruskan dan menahan aliran gelombang air. 
(2) Struktur bangunan rangka kayu (lentur) dinding semi permanen, dan beton (rigid) dinding permanen.

(3) Massa bangunan kompak, proporsi kaki-badan-atap bangunan sebanding, dapat memberikan stabilitas terhadap gaya lateral.

(4) Bentuk atap kompak dengan kemiringan atap $>20^{\circ}$, menghindari gaya angkat pada atap.

(5) Selubung bangunan bercelah memberikan pengaliran angin.

\section{Kesimpulan}

Artikel kajian ini menyimpulkan bahwa aspek tanggap bencana dapat diimplementasikan pada: (1) Lokasi bangunan terkait kesiagaan terhadap bencana pada pulau-pulau kecil yang memiliki kepadatan hunian relatif rendah. (2) Orientasi bangunan, Jarak antar-bangunan, Tipe bangunan, Struktur bangunan, Massa bangunan, Bentuk atap, dan Fasade bangunan merupakan unsur kearifan lokal teknologi arsitektur dan lingkungan yang berperan dalam kesiagaan terhadap bencana alam marin di lingkungan pulau kecil.

Kontribusi kajian ini memberikan wawasan, dan menumbuhkan kesadaran pada masyarakat pulau kecil untuk menjaga kualitas lingkungan dan bangunan sebagai upaya menciptakan wilayah pulau yang tanggap bencana.

\section{Ucapan Terima Kasih}

Artikel ini disusun berdasarkan tahap awal dari penelitian skim Unggulan Perguruan Tinggi tahun pertama 2016 yang berjudul 'Pulau Siaga Bencana: Teknologi Spesifik Arsitektur dan Lingkungan Menghadapi Perubahan Iklim di Pulau Sapuli Kabupaten Pangkajene dan Kepulauan'. Penulis menyampaikan terimakasih kepada LPPM Universitas Hasanuddin, Bapak Sekretaris Desa Mattiro Baji, segenap warga Pulau Sapuli, dan para mahasiswa Departemen Arsitektur FT Unhas yang telah membantu pelaksanaan survey.

\section{Daftar Pustaka}

Bengen, D. G. \& Tahir, A. (2012). Policy Review: Opportunities for Enhancing Community Resilience and Climate Change Adaptation in Indonesia. Indonesia Marine \& Climate Support (IMACS) Project, Coastal Resourve Center supported by USAID.

Biro Pusat Statistik. (2015). Data Statistik Kabupaten Pangkajene Kepulauan, Propinsi Sulawesi Selatan.

Dahuri, R. dkk. (1996). Pengelolaan Sumber Daya Wilayah Pesisir dan Lautan Secara Terpadu. Jakarta: PT. Pradnya Paramita.

Diposaptono, S. (2014). Rencana Zonasi Wilayah Pesisir dan Pulau-pulau Kecil (RZWP3K)/Rencana tat Ruang Berbasis Mitigasi Bencana. Materi Paparan Direktur Tata Ruang Laut, Pesisir, dan Pulau-pulau Kecil Kementerian Kelautan dan Perikanan. Yogya-karta, 25 September.

Keputusan Menteri Kelautan dan Perikanan No.59/ Kepmen-KP/2014. (2014). Rencana Pengelolaan dan Zonasi Taman Wisata Perairan Kepulauan Kapoposang dan Laut Sekitarnya di Propinsi Sulawesi Selatan 2014-2034.

Nasiah \& Suprapta. (2010). Zonasi rawan bencana marin di pantai Barat Propinsi Sulawesi Selatan. Jurnal Geografi, Departemen Geografi FMIPA-UI, Vol.3 No.1 Januari 2010, hal. 29-36. 
Pemerintah Kabupaten Pangkep. (2012). Rencana Zonasi Wilayah Pesisir dan Pulau-pulau Kecil $(R Z W P)$.

Pemerintah Kabupaten Pangkep. (2012). Gambaran Umum Potensi Wilayah Kabupaten Pangkep.

UU No. 27. 2007. Pengelolaan Wilayah Pesisir dan Pulau-pulau Kecil.

UU No.01. 2014. Perubahan atas UU No.27/2017 tentang Pengelolaan Wilayah Pesisir dan Pulau-pulau Kecil. 